\title{
IGUALDAD ENTRE MUJERES Y HOMBRES EN LA JURISPRUDENCIA DEL TRIBUNAL CONSTITUCIONAL ESPAÑOL
}

\author{
Dr. Fernando Rey MartíneZ \\ Universidad de Valladolid \\ rey@der.uva.es
}

I. Introducción. II. Igualdad de trato. II.1. Prohibición de discriminaciones directas o de trato. II.2. Prohibición de discriminaciones indirectas o de impacto. III. Igualdad de oportunidades. IV. A modo de conclusión.

\section{INTRODUCCIÓN}

El contenido del derecho fundamental a no ser discriminado por razón de sexo (art. $14 \mathrm{CE}$ ) abarca la igualdad de trato y la de oportunidades. La igualdad de trato comprende, a su vez, la prohibición de discriminaciones directas e indirectas. La igualdad de oportunidades remite al mandato de acciones positivas a favor de la igualdad real y efectiva de mujeres y hombres.

En el presente texto, se ordenará la abundante jurisprudencia del Tribunal Constitucional español ${ }^{1}$ a partir de la sucinta gramática conceptual del Derecho Antidiscriminatorio expuesta.

\section{IGUALDAD DE TRATO}

\section{II.1. Prohibición de discriminaciones directas o de trato}

Incurre en discriminación directa de género toda norma o acto que dispense un trato diferente y perjudicial en función de la pertenencia a uno u otro sexo. El TC ha estimado que son contrarias a la prohibición constitucional de discriminación por razón de sexo las siguientes discriminaciones directas:

(1a) Cláusulas de celibato, es decir, la norma (en casi todos los casos se trataba de la reglamentación de trabajo de la Compañía Telefónica Nacional de España) que suspendía el contrato de trabajo para el personal femenino por causa del ma-

${ }^{1}$ Hasta enero de 2010. 
trimonio (STC 7/1983, de 14 de febrero y, en sentido similar, 8/1983, 13/1983, 15/1983, 86/1983, 34/1984 y 59/1993).

(2a) Disposición de la ley de 19 de junio de 1971, de protección de familias numerosas, que reservaba la titularidad de cabeza de familia al padre, y a la madre sólo en defecto de aquél (STC 241/1988, de 19 de diciembre); el problema suscitado en el caso era que el empleador de la recurrente (el Consejo General de Colegios de Médicos) exigía la condición de cabeza de familia para el reingreso tras una excedencia forzosa anterior.

(3a) Norma que establecía que, en caso de separación y a falta de acuerdo de los padres, los hijos menores de siete años quedarían al cuidado de la madre, salvo que el Juez, por motivos especiales, proveyere de otro modo. La STC 144/2003 otorgó el amparo contra la aplicación judicial de esta norma (antigua redacción del art. 159 del Código Civil), que ya estaba derogada en ese momento (desde el año $1990^{2}$ ), por vulneración del art. $14 \mathrm{CE}$, "al restablecer el órgano judicial una discriminación por razón de sexo que el propio legislador ya había eliminado”.

(4a) Norma de conflicto que señalaba la nacionalidad del marido al tiempo de contraer matrimonio como punto de conexión para la determinación de la ley aplicable a las relaciones personales del matrimonio y, en defecto o por insuficiencia de capitulaciones matrimoniales, también a las relaciones patrimoniales de los cónyuges. La STC 39/2002, de 14 de febrero, sostuvo la derogación sobrevenida de esta regulación (art. 9.2 del Código Civil) por vulneración del derecho a la igualdad entre los cónyuges (art. 32.1 CE) y de la prohibición de discriminación por razón de sexo (art. $14 \mathrm{CE}$ ). El Tribunal afirma que "la mera utilización de un punto de conexión que da preferencia al varón supone en sí, superada la llamada neutralidad formal de las normas de conflicto, una vulneración del derecho a la igualdad". Y ello es así incluso aunque el resultado de la aplicación de tal norma en cada caso concreto resultare más favorable a la mujer.

(5) Cálculo judicial de indemnización discriminatorio por haberse basado en un salario que, a su vez, había sido declarado discriminatorio por razón de sexo por un órgano judicial (STC 183/2000, de 10 de julio ${ }^{3}$ ).

(6a) Discriminaciones por razón de embarazo. Han recaído sobre este asunto numerosas sentencias. El Tribunal mantiene una tendencia inequívocamente garantista. En la sentencia 166/1988, de 26 de septiembre, el Tribunal otorga el amparo a una empleada que alegaba que su contrato había sido resuelto unilate-

\footnotetext{
${ }^{2}$ La regulación actual remite al Juez la decisión de a cuál de los dos progenitores confiará el cuidado de los menores, atendiendo al beneficio de éstos.

${ }^{3}$ En la STC 183/1998 ya se apuntó esta doctrina, pero no se aplicó al caso porque no había habido previamente discriminación retributiva por razón de sexo declarada por el órgano judicial.
} 
ralmente por el INSALUD debido a su embarazo, pues correspondía al empleador la carga de probar que no fue ésta la causa de la resolución contractual. El dato de mayor interés quizás resida en que la resolución se produjo durante el período de prueba. Ya en una sentencia anterior, 94/1984, de 16 de octubre, el Tribunal había sostenido la validez del escrutinio, desde la óptica de la prohibición de discriminación, del contrato de trabajo durante el período de prueba, aunque en aquel supuesto no apreció violación del art. $14 \mathrm{CE}$.

En la sentencia 173/1994, de 7 de junio, el TC extiende más allá el ámbito de la tutela de la trabajadora grávida, reduciendo a la vez la potestad discrecional empresarial de selección del personal, ya que en el caso el empleador (el Ministerio de Cultura) no despidió a la recurrente, sino que simplemente no le renovó el contrato temporal a causa de su embarazo. EL Tribunal hace avanzar la eficacia de la prohibición constitucional de discriminación a la fase anterior a la relación laboral ya formalizada, cual es la del acceso al empleo; pues, de lo contrario, "quedarían al margen de tutela algunas de las más notorias consecuencias de la discriminación como mal social a erradicar por mandato constitucional (las especiales dificultades en el acceso al empleo de los colectivos discriminados o, en el caso de la mujer, la continuidad de su propia carrera profesional por la maternidad)".

En la sentencia 136/1996, de 23 de julio, el TC otorga el amparo por discriminación por embarazo no ya por una resolución durante el período de prueba o por la no renovación de un contrato temporal, sino directamente por un despido. En esta sentencia se establece la doctrina que se repetirá posteriormente en las sentencias 20/2001, de 29 de enero; 41/2002, de 25 de febrero; 17/2003, de 30 de enero y 98/2003, de 2 de junio de 2003. El esquema argumentativo del Tribunal se inicia con la invocación, vía art. 10.2 CE, de la normativa internacional ${ }^{4}$ y comunitaria ${ }^{5}$ específicamente aplicable para concluir que los tratos laborales desfavorables por embarazo, al afectar exclusivamente a la mujer, constituyen una discriminación por razón de sexo proscrita por el art. 14 CE. A continuación, se indica que corresponde a la trabajadora acreditar la existencia de indicios de que ha sufrido la discriminación y al empleador probar la existencia de causas suficientes,

\footnotetext{
${ }^{4}$ Según el art. 5. d) del Convenio núm 158 y Convenio núm. 103 de la OIT, la Recomendación núm 95 y la Declaración de 1975 sobre igualdad de trato y de oportunidades para las trabajadoras, también de la OIT, el embarazo no constituye causa justificada para la resolución de la relación laboral.

${ }^{5}$ De la Directiva 76/207/CEE y su interpretación por el Tribunal de Justicia de la Unión se desprende que el despido de una trabajadora por razón de su embarazo constituye una discriminación directa basada en el sexo. Esta misma Directiva protege no sólo frente al despido, sino también frente a extinciones por ausencias debidas a una incapacidad laboral motivada por los trastornos relacionados con el embarazo, frente a rescisiones temporales (no sólo indefinidas), frente a la no contratación por razón de embarazo o la no renovación, incluso aunque el estado de gestación impida ocupar desde el primer momento el puesto de trabajo.
} 
reales y serias para calificar de razonable su decisión y destruir así la sospecha de lesión constitucional generada por los indicios.

En relación con la aportación de los indicios por quien alega la discriminación, el Tribunal ha concretado en la sentencia 17/2003, de 30 de enero, que debe tratarse de "un indicio razonable de que el acto empresarial lesiona su derecho fundamental, poniendo de manifiesto el motivo oculto que se denuncia" y que dicho indicio no puede ser "la mera alegación de la violación constitucional, sino que debe permitir deducir la posibilidad de que ha podido producirse". Por su parte, el ATC 89/2000, de 21 de marzo, sostiene que tendrán "aptitud probatoria" los hechos "que sean claramente indicativos de la probabilidad de la lesión del derecho" y que "pese a no generar una conexión tan patente y, por tanto, resultar más fácilmente neutralizables, sean, sin embargo, de entidad suficiente para abrir razonablemente la hipótesis de la vulneración del derecho fundamental". Debe superarse en todo caso "un umbral mínimo" de prueba (STC 17/2003, de 30 de enero).

En el caso que dio origen a la sentencia 17/2003, citada, la sentencia impugnada ante el TC había concluido que la demandante no había aportado suficientes indicios, pero el Tribunal, tras llevar a cabo un escrutinio estricto, no concluye de modo coincidente con esta opinión, por lo que estima el amparo ${ }^{6}$. La sentencia razona que ni la sentencia del órgano judicial ordinario cumplió con el mandato de invertir la carga de la prueba, ni el empleador cumplió con su carga probatoria de que fueron otras las causas motivadoras del cese ${ }^{7}$. Por el contrario, en la STC $41 / 2002$, de 25 de febrero, el Tribunal concluye, confirmando la sentencia del tribunal ordinario, que las alegaciones del demandante no resultaron convincentes en cuanto a la existencia de indicios de discriminación ${ }^{8}$.

\footnotetext{
${ }^{6}$ En efecto, el Tribunal considera, en contra de las tesis asumidas por la sentencia impugnada, que el empleador conocía la situación de embarazo de la trabajadora, que el contrato de ésta no había expirado, que existe una conexión temporal entre el embarazo y el cese y que el argumento de que la empleadora fuera un organismo público que empleaba a 98 mujeres y 29 hombres no demuestra por sí mismo la inexistencia de discriminación porque ni está en cuestión una discriminación por razón de sexo no adjetivada, sino otra cualificada por embarazo ni el quantum de mujeres excluye la posibilidad de una discriminación singular.

${ }^{7}$ En mi opinión, se incurre por ello en cierta confusión conceptual, porque bastaría con haber apreciado que, de modo incorrecto, el órgano judicial no exigió la inversión de la carga de la prueba para estimar el amparo por violación del derecho a la tutela judicial efectiva. Dado que dicho órgano no cumplió con su obligación, mal puede el empleador desvirtuar la motivación discriminatoria. Se produce, pues, cierta indefensión del demandado desde el punto de vista del debate sobre la posible discriminación sexual.

${ }^{8}$ La empresa no conocía el embarazo y el despido no fue válido desde el punto de vista legal, porque no estaba suficientemente justificada la necesidad invocada por la empresa de amortizar el puesto de trabajo por causas organizativas, pero no se aportaron por la demandante "indicios de discriminación que prueben
} 
Respecto de la inversión de la carga de la prueba, el TC ha precisado que "no se trata de situar al demandado ante la prueba diabólica de un hecho negativo (la no discriminación), sino ante la carga de probar, sin que le baste intentarlo, la razonabilidad y proporcionalidad de la medida adoptada y su carácter enteramente ajeno a todo propósito contrario a la igualdad" (STC 98/2003, de 2 de junio). Esta carga probatoria opera también en los casos de decisiones discrecionales (como, por ejemplo, el libre nombramiento y cese de cargos de confianza) que no precisan ser motivadas, pero que no por ello se sustraen al respeto de los derechos fundamentales.

En la sentencia 98/2003 el Tribunal estimó el amparo presentado por una trabajadora que ocupaba la jefatura de la secretaría de un consejero regional, pues fue cesada formalmente por "errores e incumplimientos en el desempeño de sus funciones", pero, en realidad, por haberse quedado embarazada. Dada tal divergencia, éste sería un buen ejemplo de discriminación directa oculta. El TC no consideró "verosímiles" las razones que aportó el empleador para despedirla?. También falló en sentido semejante en la STC 136/1996, de 23 de julio ${ }^{10}$.

Resulta reseñable también la STC 20/2001, de 29 de enero, que extiende la licencia por embarazo a toda funcionaria, también a las de carácter interino. La Administración había fundado el cese de manera directa e inmediata en el hecho de que la actora "no cumplía los requisitos de idoneidad que permitían continuar sustentando el nombramiento como funcionaria interina al hallarse, precisamente, en situación de baja por maternidad". En su opinión, "la Administración no debe soportar las consecuencias de tal circunstancia”. La sentencia impugnada había validado esta interpretación, considerando que la demandante no había aportado término adecuado de comparación, ya que no podría ser conceptuado como tal el status de los funcionarios de carrera a fin de extender a los interinos el régimen previsto para aquéllos. El TC se desmarca por completo de esta lectura, estimando, por el contrario, que la diferencia de trato sufrida por la demandante había incurrido en discriminación por razón de sexo ${ }^{11}$.

la existencia de un fondo o panorama discriminatorio general o, al menos, de hechos de los que surja la sospecha vehemente de una discriminación por razón de embarazo".

${ }^{9}$ La demandante había trabajado para el empleador sin problema alguno durante los dos años anteriores hasta que quedó embarazada; la Administración empleante no explicitó en momento alguno las razones concretas del incumplimiento del que se acusaba a la trabajadora, etc.

${ }^{10}$ Ciertamente, la recurrente había faltado al trabajo varias veces (por lo cual fue despedida), pero lo había hecho por causa de su embarazo, que era conocido por la empresa. El TC estimó el amparo.

${ }^{11}$ Y por este motivo, al no ser un caso de igualdad en general, sino de discriminación en particular, no haría falta aportar término de comparación. 
Las últimas sentencias relativas a la protección constitucional de la mujer embarazada son la STC 161/2004, de 4 de octubre, la 175/2005, de 4 de julio y la 182/2005, de la misma fecha, la STC 214/2006, de 3 de julio, la 324/2006, de 20 de noviembre, la 342/2006, de 11 de diciembre, la 17/2007, de 12 de febrero, la 74/2008, de 23 de junio, la 92/2008, de 21 de julio y la 124/2009, de 18 de mayo. En el caso que dio origen a la primera de ellas, una mujer piloto fue calificada por su empresa como "no apta circunstancial" por razón de embarazo, por lo que le fue suspendido su contrato de trabajo en tanto que se encontraba imposibilitada parta desempeñar sus funciones como piloto y no se le podía ofrecer un puesto distinto por falta de vacantes. El Tribunal Constitucional considera, sin embargo, que la empresa la discriminó por razón de sexo, puesto que tendría que haberle ofrecido un puesto de trabajo en tierra adecuado a la situación de la demandante y viable en su estado de embarazo.

En la STC 175/2005, el Tribunal otorga el amparo a una auxiliar de clínica que en el plazo de año y medio había sido contratada continuadamente en catorce ocasiones, de modo interino o eventual, hasta cuando la empresa conoció su embarazo, momento a partir del cual ya no se la ofreció renovación alguna. La sentencia aprecia indicios racionales de discriminación por embarazo que la empresa no habría rebatido.

Destacable es la STC 182/2005, porque extiende la protección constitucional de la trabajadora embarazada no ya frente al despido o no renovación de su contrato, sino frente a la obstaculización de su promoción profesional. Sin duda, esta sentencia inaugura una línea de tutela (quizás más conectada al concepto de discriminación "indirecta" que "directa", aunque en la sentencia no se aluda a ello) que podrá ser seguida en el futuro por otros casos. La sentencia otorgó el amparo a una trabajadora a la que su empresa había ido asignando tareas de menor entidad, primero, y cambiado a un puesto de trabajo distinto y de menor responsabilidad, más tarde, como consecuencia de su triple maternidad. La empresa no habría aportado ninguna prueba que desvirtuara el nexo causal entre la creciente minusvaloración profesional de la trabajadora y sus tres embarazos.

En la STC 214/2006, el Tribunal otorga protección a una trabajadora embarazada que había sido excluida por este motivo por el INEM de la relación de candidatos para responder a una determinada oferta de empleo. La sentencia considera que el fin proteccionista de esta decisión constituyó, pese a todo, una discriminación sexual prohibida por el art. 14 CE. En la STC 324/2006 concedió el amparo a una trabajadora que había perdido sus vacaciones anuales, sin compensación alguna, después del permiso de maternidad (por haber terminado el año natural). La sentencia estimó que se había causado un perjuicio a la traba- 
jadora a causa de su embarazo y maternidad. En la STC 342/2006, el Tribunal tuteló a una trabajadora que había sido despedida porque los órganos judiciales no habían apreciado el indicio de discriminación que había presentado (entre otros, que había sido despedida poco después de comunicar a la empresa su embarazo) y, por tanto, no había sido rebatida la presunción de discriminación sexual por razón del embarazo.

En la sentencia 17/2007, el Tribunal también otorgó el amparo a una trabajadora que había sido despedida formalmente por no haber superado un período de prueba, pero en realidad, dado que esa trabajadora ya había tenido un contrato temporal con esa misma empresa (con el período de prueba correspondiente), había sido despedida por las frecuentes bajas laborales que había tenido a causa de su embarazo de alto riesgo. El Tribunal Constitucional censura duramente el razonamiento del órgano judicial ordinario que había venido a justificar el despido por el bajo rendimiento de la trabajadora debido a las "enfermedades" derivadas de un embarazo problemático.

En el año 2008 han recaído dos sentencias sobre esta materia. La primera, $74 / 2008$, otorga amparo reiterando la consolidada doctrina sobre prueba indiciaria: se considera que, habiéndose aportado por la actora un indicio razonable de que la no renovación de los contratos anuales que venía suscribiendo podía estar motivada por su embarazo, el Ayuntamiento no desvirtuó la presunción de discriminación. Más innovadora resulta la sentencia 92/2008, ya que la trabajadora embarazada fue despedida sin que constase que el empresario conociera su estado ni se hubiese comunicado el embarazo y, sin embargo, el Tribunal declara ese despido discriminatorio y nulo. El Tribunal argumenta que la nulidad del despido prevista en la legislación española es automática y objetiva y no requiere acreditar el previo conocimiento por parte del empresario del estado de embarazo de la trabajadora. Esta misma doctrina se vuelve a aplicar en la sentencia 124/2009, pero es discutible, como lo prueba que el mismo Magistrado (Vicente Conde) que firma la ponencia de la sentencia emite un voto particular discrepante. El problema es el siguiente. La redacción que en 1999 se da al art. 55.5 del Estatuto de los Trabajadores permite declarar nulo el despido de las trabajadoras embarazadas desde la fecha de inicio de su embarazo, salvo que se declare la procedencia del despido por motivos no relacionados con el embarazo. Esta disposición se aleja de la regulación de la Directiva 92/85 (que precisamente transpone en el ordenamiento español), porque, para la protección de la trabajadora embarazada, la norma europea expresamente prevé la necesidad de comunicación del estado de embarazo al empleador. El Tribunal español considera, sin embargo, que la norma europea marca tan sólo un nivel mínimo de protección, pudiendo ir la legislación 
nacional más allá, como es el caso. El voto discrepante sostiene, por el contrario, que no puede hablarse de despido discriminatorio por razón de embarazo si el embarazo no se conoce.

(7a) En el capítulo de las discriminaciones directas, hay que llamar la atención sobre dos sentencias de gran valor simbólico e histórico: la que considera que la inadmisión por el Ministerio de Defensa de una mujer a las pruebas para el ingreso en la Academia General del Aire es una medida contraria al art. 14 CE (STC 216/1991, de 14 de noviembre), y la que declara inconstitucional el art. 1 del Decreto de 26 de julio de 1957 que prohibía el trabajo de la mujer en el interior de las minas (STC 229/1992, de 14 de diciembre). En esta última sentencia el TC concede el amparo a la recurrente, estimando su pretensión de ocupar en igualdad con los trabajadores varones una plaza de ayudante minero en HUNOSA, que le había sido denegada por la empresa (en aplicación del art. 1 del Decreto citado), a pesar de haber superado la prueba de admisión. Tanto la sentencia laboral de instancia como la de suplicación habían considerado que la prohibición del trabajo de las mujeres en las minas era conforme con el art. $14 \mathrm{CE}$, en la medida en que se trataba de una norma protectora de las mujeres. Pero el TC no lo entiende así; dicha prohibición, aunque responde históricamente a una finalidad tuitiva, evitar la sobreexplotación del trabajo femenino, no es una medida de acción positiva o de apoyo para conseguir una igualdad real de oportunidades, ya que no favorece el trabajo de las mujeres, sino que le restringe. En efecto, "hay que vigilar con particular reserva (y periódicamente)" las medidas protectoras pues pueden basarse, realmente, en prejuicios infundados que responden a una "división sexista del trabajo", o bien que por las mejoras en las condiciones de trabajo, como ha ocurrido en las minas, han perdido su razón de ser. En el caso, la sentencia señala como prejuicio sexista en presencia el de la menor fortaleza física de la mujer respecto del hombre; un estereotipo que más que reforzar una diferencia "real, natural o biológica”, limita o perjudica a la mujer en el mercado de trabajo. Este aspecto será analizado con detalle en los casos de discriminación indirecta.

(8a) Supuestos de acoso sexual. La sentencia del Tribunal Constitucional 224/1999 tiene el mérito de haber configurado por primera vez el acoso sexual como una forma de discriminación sexual ${ }^{12}$ (así como una violación del derecho a la intimidad del art. 18.1 CE). Para que pueda apreciarse un acoso sexual el Tribunal exige "una conducta de tal talante por medio de un comportamiento físico o verbal manifestado en actos, gestos o palabras", comportamiento "que se

\footnotetext{
${ }^{12}$ Pues "afecta notoriamente y con mayor intensidad a la mujer que al hombre, como consecuencia de condiciones históricas de inferioridad o debilidad de ellas en el mercado de trabajo y en el lugar de su prestación" (f. jco. 5).
} 
perciba como indeseado e indeseable por su víctima" y que "sea grave, capaz de crear un clima radicalmente odioso e ingrato". La sentencia 136/2001 también resuelve un caso de acoso sexual, pero en este caso, el Tribunal confirma la sentencia del Supremo que no había considerado suficientes los indicios aportados por la recurrente ${ }^{13}$, por lo que desestima el amparo.

(9) Todos los casos de discriminaciones directas resueltos por el Tribunal merecen, a mi juicio, una valoración positiva, menos uno. La sentencia 126/1997, de 3 de julio, va a declarar no contraria al art. $14 \mathrm{CE}$ una no negada discriminación directa, la regla de la preferencia del varón sobre la mujer en el orden regular de las transmisiones hereditarias de los títulos nobiliarios (contenida en la Partida 2.15.2, en vigor). Más exactamente, el TC estima que no es de aplicación en este caso el típico examen judicial estricto sobre cualquier posible discriminación sexual, pues "admitida la constitucionalidad de los títulos nobiliarios por su naturaleza meramente honorífica y la finalidad de mantener vivo el recuerdo histórico al que deben su otorgamiento, no cabe entender que un determinado elemento de dicha institución -el régimen de su transmisión mortis causa- haya de apartarse de las determinaciones establecidas en la Real carta de concesión". En otras palabras, el derecho de nobles sería resistente frente a la prohibición constitucional de discriminación por razón de sexo por tratarse de un derecho histórico, de escaso significado (tan sólo honorífico-simbólico) y, sobre todo, de estricto carácter privado (vale decir, un auténtico derecho de particulares en el sentido con que acuñó este concepto C. Sforza). Los votos particulares de los Magistrados C. Viver, T. Vives y P. Cruz resultan, empero, más convincentes. El orden regular de sucesión de los títulos nobiliarios, al que es aplicable la Constitución y su art. 14, es una discriminación frontal por razón de sexo, pues dicho orden se establece en una norma jurídica (y no en "una simple regla de comportamiento establecida por determinados grupos sociales en virtud de sus particulares convenciones") y los actos de concesión, rehabilitación y transmisión mortis causa de los títulos nobiliarios no son fruto tampoco de relaciones inter privatos, sino ejercicio de facultades públicas del Monarca (art. $62 \mathrm{f}$ ), en el que intervienen diversos órganos estatales (desde el Consejo de Estado hasta los órganos judiciales, pasando por el refrendo

\footnotetext{
${ }^{13}$ Habían sido una comida con el presidente de la empresa, el supuesto acosador; tres testimonios de compañeros y un cuadro médico de ansiedad. El TC apreció que, en el tiempo de los hechos, la demandante estaba tramitando su separación, lo que también podría explicar su estado de ansiedad. La sentencia afirma que "dado que no podemos alterar la valoración de la prueba efectuada por el Tribunal Supremo... hemos de concluir que no se ha producido la vulneración denunciada sin descartar la realidad psicológica del acoso que la actora dice haber sufrido... los hechos psicológicos sólo pueden probarse a través de hechos físicos y de los aquí presentados no cabe extraer, razonablemente y habida cuenta de los límites de nuestra jurisdicción, la existencia de una situación discriminatoria o lesiva del derecho fundamental".
} 
del Ministro de Justicia), "y todo este proceso está regido por normas cuyo contenido no se limita a reconocer un ámbito de autonomía de la voluntad o privada, sino que establecen auténticas reglas de ius cogens, plenamente integradas, y esto es aquí lo más relevante, en el ordenamiento jurídico vigente en la actualidad en España”. Aunque los títulos nobiliarios sean hoy un simple nomen honoris de escasa trascendencia, sus efectos jurídicos no son ni inexistentes ni irrelevantes (como demuestra la importante litigiosidad judicial que suscitan), se integran en el "patrimonio inmaterial" de ciertos individuos y, además, "el valor de los derechos fundamentales no se mide por el número de sus posibles titulares ni por el mayor o menor alcance de sus consecuencias jurídicas o prácticas". Sin olvidar el prejuicio profundamente odioso que está en el origen histórico de esta preterición de la mujer: su incapacidad para transmitir el linaje en condiciones de igualdad con el hombre y, en definitiva, la inferioridad de la mujer. Por otro lado, la tesis de que si la Constitución acepta la pervivencia de una institución histórica debe admitirla tal como es, sin exigir ninguna adaptación (sint ut sunt aut non sint: sean como son o no sean, según sentenció el Papa Clemente XIII para negarse a modificar las Constituciones de S. Ignacio), es muy endeble desde el punto de vista jurídico. Por una parte, el orden regular de transmisión mortis causa no es un elemento basilar de la institución, por otra, y, sobre todo, los títulos nobiliarios también tienen que adaptarse a la Constitución, al Estado de los derechos fundamentales ("la publicatio de los títulos nobiliarios tiene el pequeño coste derivado de la circunstancia de vivir en una res publica constitucional").

$\left(10^{a}\right)$ Exigencia de determinada apariencia física en el ámbito laboral: STC 84/2006, de 27 de marzo. Un sindicado, CGT, demandó a RENFE porque obligaba a utilizar falda a las empleadas que servían en el tren de alta velocidad, sin darles la posibilidad de vestir pantalones. Los dos órganos judiciales ordinarios que conocieron previamente el caso habían entendido que ello no violaba los derechos de las trabajadoras, porque no suponía un ataque a su honor y dignidad. El asunto no pudo, sin embargo, ser resuelto por el Tribunal Constitucional porque RENFE y los sindicatos pactaron antes la posibilidad de que las trabajadoras pudieran elegir entre la falda y el pantalón, por lo que hubo una satisfacción extra-procesal de la pretensión. Es una lástima que el Tribunal Constitucional no se pronunciara sobre el problema de la vestimenta de los trabajadores (cuya determinación corresponde, en principio, a los empleadores) en relación con la discriminación que en algunos casos puede producirse contra las trabajadoras.

(11 a) Otra sentencia a tener en cuenta es la STC 3/2007, de 15 de enero. El Tribunal se enfrenta a unas decisiones judiciales ordinarias que habían denegado a una trabajadora el derecho de reducción de jornada por guarda legal de hijos 
menores de seis años al interpretar que no cabía en lo que el precepto aplicable del Estatuto de los Trabajadores denomina "jornada ordinaria". La sentencia incorpora los conceptos de derecho antisdiscriminario provenientes del ordenamiento comunitario europeo y concluye que la conciliación entre vida personal y profesional deriva de la prohibición de discriminación sexual (art. $14 \mathrm{CE}$ ) y tiene, por tanto, "dimensión constitucional", de modo que tiene carácter de principio interpretador: "la dimensión constitucional de la conciliación ha de servir de orientación para solución de cualquier duda interpretativa". La sentencia es, en cierta medida, innovadora porque reconoce el carácter de "principio" (y no ya el de regla) de la prohibición constitucional de discriminación sexual. El Tribunal Constitucional otorga el amparo, porque estimó que el juez ordinario había interpretado la ley sin haber ponderado el derecho fundamental.

\section{II.2. Prohibición DE DISCRIMINACIONES INDIRECTAS O DE IMPACTO}

Son discriminaciones indirectas aquellos tratamientos jurídicos formalmente neutros respecto del sexo, pero de los que derivan, por la desigual situación fáctica de los hombres y mujeres afectados, consecuencias desiguales perjudiciales por el impacto diferenciado y desfavorable que tienen sobre los miembros de uno y otro sexo (de ahí que a este tipo de discriminación se la denomine también "discriminación de impacto"). La doctrina de la discriminación indirecta fue inicialmente de acuñación jurisprudencial entre nosotros, antes de su reconocimiento en la Ley orgánica de igualdad entre mujeres y hombres. El TC ha incorporado el concepto de discriminación indirecta, aunque no sin ciertas oscilaciones. La STC 145/1991, de 1 de julio, es la que lo introduce, con cita expresa de la jurisprudencia del Tribunal de Justicia de la Unión Europea (que, a su vez, lo toma de la jurisprudencia del Tribunal Supremo norteamericano, desde la sentencia Griggs v. Duke Power Company, de 1971). Las recurrentes en amparo son limpiadoras de un hospital público que pedían el mismo salario que los peones, pues venían realizando igual trabajo y, sin embargo, percibían, según convenio colectivo, inferior sueldo. El TC les otorga el amparo por entender que eran víctimas tanto de una discriminación directa (según el principio de igual retribución por trabajo de igual valor) como indirecta: desigual valoración (adoptando como criterio determinante el sexo) de trabajos equivalentes desde el punto de vista de la naturaleza y condiciones de la prestación. La prohibición constitucional de discriminación comprende también las discriminaciones indirectas, que la STC define como "tratamientos formalmente no discriminatorios de los que derivan, por las diferencias fácticas que tienen lugar entre trabajadores de diverso sexo, consecuencias desiguales perjudiciales por el impacto diferenciador y desfavorable que tratamientos formalmente iguales o 
razonablemente desiguales tienen sobre los trabajadores de uno y otro sexo a causa de la diferencia sexual". En el caso en examen, no le satisface al TC la justificación de la razonabilidad de la diferencia entre las categorías de "peones" y de "limpiadoras" que había observado el órgano judicial ordinario (la mayor penosidad y esfuerzo físico que caracteriza a la figura de peón). Este criterio, afirma el TC, es "una premisa no demostrada... que otorga mayor valor injustificadamente a una cualidad predominantemente masculina, desconociendo otras características del trabajo (atención, cuidado, responsabilidad, etc.) más neutras en cuanto a su impacto en cada uno de los sexos". La misma denominación de "limpiadoras" es calificada por el TC de discriminatoria.

La STC 58/1994, de 28 de febrero, profundiza en los criterios de valoración sobre si han de considerarse o no de igual valor los trabajos desempeñados preferentemente por mujeres respecto de los trabajos, mejor retribuidos, realizados preferentemente por hombres. El problema planteado por el asunto era el de si constituía una discriminación el hecho de que las empleadas de las secciones de envasado y expedición de la empresa Antonio Puig S.A., a pesar de ostentar categorías profesionales superiores o equivalentes a las de sus compañeros de las mismas secciones, percibían una retribución mensual sensiblemente inferior. El TC aprecia una discriminación prohibida, pues el empleador no justificó suficientemente la diferencia de trabajos entre hombres y mujeres en orden a concederles una retribución distinta y, además, el único criterio de diferencia que mencionó fue el del "mayor esfuerzo físico" de los varones, criterio que, formulado aisladamente, es sexista. Remitiéndose a la sentencia Enderby del Tribunal de Justicia de la Unión Europea, de 27 de octubre de 1993, el TC aísla tres reglas generales: ( $\left.1^{a}\right)$ en los supuestos en los que existan categorías predominantemente ocupadas por trabajadores de uno u otro sexo, desigualmente retribuidas, y no exista transparencia en la determinación de los criterios retributivos, corresponde al empleador la carga de poner de manifiesto los citados criterios, a fin de excluir cualquier sospecha de que el sexo haya podido ser el factor determinante de dicha diferencia; ( $\left.2^{a}\right)$ el parámetro de igualdad no es aquí la igualdad de tareas, sino la igualdad del valor del trabajo; ( $3^{a}$ ) en la valoración del trabajo ha de garantizarse que los criterios de evaluación no sean, por sí mismos, discriminatorios, sino que se trate de criterios neutros.

EL TC aplica estos criterios en la sentencia 147/1995, de 16 de octubre, al identificar como discriminación indirecta la diferencia retributiva del distinto trabajo, pero de igual valor, de las mujeres (envasado y control estadístico) y de los varones (mezclas, moldeado y bombas de satinado) dentro de una empresa. El empleador no logró probar que los criterios de diferencia retributiva fueran 
neutrales, ni su valoración fue objetiva y transparente, con lo que no consiguió desvanecer la apariencia discriminatoria. Pero, aplicando estos criterios, falló, en la sentencia 250/2000, conforme a Constitución la utilización del esfuerzo físico como criterio diferencial del valor salarial atribuido a las categorías masculinizadas de "cargadores, de cargadores y apiladores" (en el Convenio de Manipulación y Envasado de Agrios de la región murciana de 1994) frente a las de "marcadoras, triadoras y encajadoras". Para el Tribunal es definitivo que es función de los "cargadores", etc. "el permanente manejo de... cargas de 20 kilos de peso", con el consiguiente "riesgo dorsolumbar que la constante exigencia física que esa actividad entraña”. El TC, después de reiterar su doctrina, confirmó la sentencia del tribunal ordinario que había considerado que el criterio del mayor esfuerzo físico era, en el caso en examen, un factor esencial en la tarea de que se trataba y no era el único criterio de valoración, por lo que estaba correctamente establecido y, por tanto, no había violación del art. $14 \mathrm{CE}^{14}$.

La STC 286/1994, de 27 de octubre, da un paso atrás en la línea jurisprudencial establecida por las SSTC 145/1991 y 58/1994 (y que volverá a recuperar en la STC 147/1995). También en este caso parece existir una segregación profesional por razón del sexo en una empresa de fabricación de galletas: mientras que a los varones se les confiaba la producción (es decir, la manipulación de las materias primas y la creación del producto), a las mujeres se las derivaba normalmente hacia el departamento de envasado, empaquetado y acabado. Como es de suponer, a esta función se la asignaba un menor nivel retributivo, e incluso las pocas mujeres que trabajaban en el departamento de producción recibían una remuneración inferior a la de sus compañeros varones. La STC sostiene que "es muy probable que en la génesis de la segregación profesional de los trabajos... estuviera una vez más la idea preconcebida de la menor fortaleza física y de cierta debilidad de la mujer en relación con el varón", y califica esta distinción como "anacrónica” y "estereotipada"; pero no advierte en ella una discriminación indirecta, pues la división sexista de tareas no fue objeto de debate en los procesos judiciales ordinarios y, además, porque admitiendo el principio de Derecho Comunitario de igual retribución por trabajos de igual valor (y no sólo por trabajos idénticos), entiende que las funciones de producción y de envasado no tienen el mismo valor, sino que la primera exige mayor responsabilidad, por lo cual es lógico que esté mejor retribuida. Por supuesto, el TC sí apreció la discriminación directa que sufrían las mujeres que trabajaban en la sección de producción, pero no la discriminación indirecta de la clasificación de funciones dentro de la empresa en atención al sexo, lo que es

\footnotetext{
${ }^{14}$ Encuentro, no obstante, discutible que se niegue a priori la posibilidad de que alguna mujer pudiera desempeñar un trabajo de esta naturaleza.
} 
muy discutible a la vista de los criterios comunitarios que el TC hizo suyos en la STC 58/1994.

La STC 198/1996, de 3 de diciembre, ofrece también una solución criticable al problema planteado, que, por otra parte, es bastante curioso: la recurrente se presentó y aprobó unas pruebas de auxiliar administrativo con destino en la administración autonómica madrileña; posteriormente, dicha administración asimila el puesto de "basculero" al de auxiliar administrativo y adscribe la recurrente a dicho puesto; la Comunidad de Madrid, finalmente, decide resolver la relación laboral porque la actora no posee la fuerza física necesaria para realizar el trabajo de basculera (algunas operaciones de montaje de la báscula para pesar los vehículos requerían notable fuerza física). EL TC no aprecia discriminación indirecta basándose en que el puesto de trabajo se ha definido conforme a criterios neutros y está abierto a trabajadores de ambos sexos (de hecho, la integración de los basculeros en la categoría de auxiliar administrativo se efectuó para evitar la "masculinización" de la tarea de basculero) y, además, si las funciones de basculero requieren poseer una fortaleza física superior a la media de las mujeres, ello por sí solo no resulta discriminatorio y contrario al art. $14 \mathrm{CE}$, toda vez que se trata de un factor requerido por la propia naturaleza del trabajo (otra cosa son las consecuencias que se atribuyan a esa mayor fortaleza física, pues si se hipervalora a efectos retributivos en detrimento de otras características más comunes y neutras en cuanto al impacto en ambos sexos, se lesionaría el art. $14 \mathrm{CE}$ ). En su voto discrepante, Vicente Gimeno entiende, por el contrario, que "cuando se oferta un puesto que no requiere esfuerzo físico alguno y posteriormente se le obliga a la mujer a realizar otro (aunque se encuentre dentro de la misma categoría profesional) que no puede ejercitar porque carece de la fuerza necesaria, y se procede, por esa sola causa, a su despido, el empleador ha creado, en la práctica, una discriminación por razón de sexo que debiera haber sido amparada por este Tribunal"; máxime si dicha conducta la observa una Administración Pública.

Hay que mencionar también la saludable STC de 22 de marzo de 1999, que ha concedido el amparo a un sindicato porque el TSJ que conocía de un proceso en el que se discutía la política de contratación casi exclusivamente en favor de varones de una empresa (Fasa), se negó a incorporar al proceso ciertos documentos que hubieran acreditado indicios suficientes de discriminación (por ejemplo, en un año Fasa contrató 120 varones y ninguna mujer) y hubieran permitido, en ese caso invertir la carga de la prueba, correspondiendo a la empresa probar que su política de contratación era objetiva y ajena a toda intención discriminatoria. Finalmente, la sentencia del Tribunal Supremo (Sala de lo Social), de 4 de mayo de 2000, estimó la pretensión del sindicato declarando que la empresa habría incurrido 
en una conducta discriminatoria indirecta en su política de contratación, ya que la empresa no aportó una justificación objetiva y razonable de por qué exigía el título de Formación Profesional-2 para realizar unas funciones que no requerían tan formación, siendo "desproporcionado y perjudicial para el colectivo femenino que por razones socio-económicas no suele poseer tan título". Por su similitud, esta sentencia bien podría calificarse como la sentencia "Griggs" española.

En la sentencia 240/1999, de 20 de diciembre (cuya doctrina se reitera en la sentencia 203/2000, de 24 de julio), el TC aborda el problema de la denegación de la excedencia para el cuidado de los hijos a las funcionarias interinas, concluyendo que esta medida resulta contraria al art. $14 \mathrm{CE}$ (por lo menos, en el caso de funcionarias interinas que lleven más de cinco años ocupando su plaza). No niega el Tribunal que "el interés público de la prestación del servicio puede, en hipótesis, justificar un trato diferenciado entre el personal estable e interino al servicio de la Administración", pero "cuanto más tiempo lleva el personal interino en el puesto, más injustificadas son las diferencias de trato". Por otro lado, la excedencia para el cuidado de los hijos menores "coopera al efectivo cumplimiento del deber de los padres de prestar asistencia a los hijos (art. 39.3 CE)", "garantiza el instituto de la familia (art. 39.1 CE)" y "promueve la conciliación entre la vida familiar y laboral de los trabajadores cuyo fundamento se encuentra en los art. 39.1 y 9.2 CE", por todo lo cual "tiene dimensión constitucional". Excluir a los funcionarios interinos de este tipo de excedencia sería una discriminación indirecta, porque "en el ámbito laboral la denegación de esta posibilidad supone un obstáculo muy importante a la permanencia de las mujeres en el mercado de trabajo", pues "hoy por hoy son las mujeres las que de forma casi exclusiva solicitan este tipo de excedencia y, en consecuencia... en caso de denegación sólo las mujeres se ven obligadas a abandonar su puestos de trabajo".

La STC 253/2004, de 22 de diciembre, puede calificarse como una magnífica sentencia. Y no tanto por su fallo, ya que el artículo 12.4 del Estatuto de los Trabajadores que fue impugnado en la cuestión de inconstitucionalidad ("Para determinar los períodos de cotización y de cálculo de la base reguladora de las prestaciones de la Seguridad Social, incluida la protección por desempleo, se computarán exclusivamente sobre las horas trabajadas"), había sido modificado posteriormente, cuanto por su argumentación. Quizás sea la sentencia que con mayor entusiasmo acoge el concepto de discriminación indirecta, lo cual pueda explicarse por el significativo desarrollo que ha experimentado recientemente el Derecho Comunitario en este sentido (el fundamento jurídico $7^{\circ}$, por cierto, incorpora el análisis más completo y actualizado del Derecho de la Unión, especialmente, de la capital Directiva 76/207 -modificada por la Directiva 2000/73-). 
El Tribunal entiende que la regulación vulnera el principio de igualdad en la ley y también el derecho a no sufrir discriminación (indirecta) por razón de sexo. En efecto, sostiene, por un lado, que no es contrario al art. $14 \mathrm{CE}$ que el trabajo a tiempo parcial conlleve una pensión de cuantía proporcionalmente inferior a la de un trabajador a tiempo completo ya que implica un esfuerzo contributivo menor, pero la aplicación del criterio de proporcionalidad en sentido estricto a los contratos a tiempo parcial a efectos del cómputo de los períodos de carencia necesarios para causar derecho a las prestaciones conduce a un resultado "desproporcionado", pues dificulta injustificadamente el acceso de los trabajadores a tiempo parcial a la protección social al exigir períodos de carencia más exigentes que a los trabajadores a tiempo completo.

Pero, y esto es lo más novedoso de la sentencia, el Tribunal enjuicia también la cuestión desde la perspectiva del concepto de discriminación indirecta, concluyendo que el precepto legal impugnado incurría en ella porque "el contrato a tiempo parcial es una institución que afecta de hecho predominantemente al sexo femenino, lo que obliga a examinar con mayor cautela el impacto de la regla sobre cómputo de períodos de carencia”. La sentencia se valió (como suele ser habitual en los casos de discriminación indirecta) de estadísticas (del Instituto de la $\mathrm{Mu}$ jer) que revelaban que, en 1996, el 75,16\% de los contratos a tiempo parcial los desempeñaran mujeres y, en 2004, esta cifra se elevaba al $81,94 \%$. De modo que una regulación legal como la cuestionada que trataba de modo desproporcionado a los trabajadores a tiempo parcial respecto de los que lo son a tiempo completo (pues les dificultaba al máximo el acceso a las prestaciones sociales -otra cosa es que la cuantía de las mismas sean legítimamente desiguales a favor de los últimos), al impactar mayoritariamente sobre las trabajadoras, producía una discriminación indirecta por razón de sexo prohibida por la Constitución.

Esta línea expansiva del concepto de discriminación sexual indirecta se rompe abruptamente, sin embargo, con el Auto de 17 de abril de 2007. El Tribunal va a inadmitir a trámite, por "notoriamente infundada", una cuestión de inconstitucionalidad planteada por el juzgado de lo social número 1 de Guadalajara contra el art. 140.2 en relación con el art. 109.1.1 del Texto refundido de la Ley General de la Seguridad Social por presunta vulneración del art. $14 \mathrm{CE}$. El juez proponente entendía que los períodos en los que la mujer trabaja a tiempo parcial por haberse acogido al derecho de reducción de jornada por cuidado de hijo menor de seis años o familiar a cargo (art. 37.5 Estatuto de los Trabajadores) deberían computarse como si se hubiera desempeñado la jornada a tiempo completo a efectos del cálculo de la base reguladora de la pensión de incapacidad permanente. El Tribunal Constitucional observa que lo que plantea el juez es, en realidad, una 
inconstitucionalidad por omisión o insuficiencia normativa en la medida en que el legislador no ha contemplado expresamente, al establecer la regla general de cálculo de la base reguladora de las pensiones por incapacidad permanente una regla específica referida al caso de la reducción de jornada del art. 37.5 ET. Al no hacerlo así, según el juez proponente, se habría producido una discriminación indirecta contra las trabajadoras por ser ellas las que, según demuestra contundentemente las estadísticas, se acogen a tal modalidad de conciliación (en supuestos como éste, el Tribunal puede declarar inconstitucional el precepto, aunque no nulo, ya que eso no repara en nada la inconstitucionalidad y provoca un vacío normativo; ha de ser el legislador el que, en un "plazo razonable" solucionara la tacha de inconstitucionalidad). Por consiguiente, la pensión tendría que calcularse no sobre lo efectivamente cotizado, sino sobre las cotizaciones que se habrían efectuado de haberse mantenido la trabajadora en tal período en jornada completa.

Este razonamiento no convence, empero, al Tribunal. Reconoce que es "innegable" que son mayoritariamente las trabajadoras quienes se acogen al derecho de reducción de jornada, con la consiguiente reducción proporcional de salario y de cotizaciones a la seguridad social. Reconoce también que esta menor cotización puede afectar a la cuantía de una eventual pensión por invalidez permanente (u otras prestaciones de la seguridad social) que puedan en el futuro causarse por la trabajadora que se haya acogido al derecho de reducción de jornada. Pero no encuentra que la carencia en la ley de la seguridad social de una excepción a la regla general para este tipo de casos sea una discriminación por razón de sexo. Recordando que la STC 253/2004 consagró la plena constitucionalidad del principio de contributividad (esto es, de que las prestaciones de la seguridad social se calculen en función de las cotizaciones efectivamente realizadas), sostiene que es al legislador a quien corresponde, en atención a las circunstancias económicas y sociales imperativas para la viabilidad y eficacia del sistema de seguridad social, decidir acerca del grado de protección que han de merecer las distintas necesidades sociales.

Así pues, el Tribunal mantiene una postura formalista y sex-blind sobre este particular y pierde la oportunidad de haber concretado las sugerentes afirmaciones que para la igualdad real entre trabajadoras y trabajadores en este punto había vertido en la anterior STC 253/2004. Este Auto viene, sin embargo, acompañado por un voto particular (firmado por la presidenta, Ma Emilia Casas y por Elisa Pérez, las dos únicas magistradas del Tribunal en el momento en que dictó la resolución) que considera que el trabajador que reduce su jornada hace valer un derecho legal (art. $37 \mathrm{ET}$ ), pero con fundamento constitucional (art. 39.1 CE, que obliga a los poderes públicos proteger a las familias); de ahí que el legislador haya de tener 
en cuenta todas sus posibles repercusiones (sorprende, no obstante, que este voto no recordara el antecedente de la STC 3/2007, donde el Tribunal había elevado el principio de conciliación a rango de principio constitucional orientador de la legislación). Ejercer ese derecho no puede suponer para el trabajador un perjuicio o un trato peyorativo. Dado que son las mujeres quienes mayoritariamente se acogen a este derecho de reducción de jornada, las trabajadoras no se encuentran en la misma situación, sino peor, que otros trabajadores que prestan sus servicios a tiempo parcial o reducen su jornada por razones diferentes. Habría una clara discriminación sexual indirecta. Yo también lo creo así.

Un último ejemplo de discriminación indirecta, aunque tal calificación es discutible en este caso, lo proporciona la importante sentencia 59/2008, de 14 de mayo, que resuelve una cuestión de inconstitucionalidad planteada por el Juzgado de lo Penal número 4 de Murcia respecto de la redacción que el art. 37 de la Ley Orgánica de Violencia ha dado al art. 153.1 del Código Penal, fallando que la norma penal que castiga más a los hombres cuando maltraten a sus mujeres o ex mujeres que a las mujeres cuando maltraten a sus parejas varones es conforme con la Constitución. Concretamente, la pena para el varón que, de cualquier modo, cause menoscabo psíquico o lesión (que no fueran constitutivos de delitos) o golpeare o maltratare (sin causar lesión) a la esposa o pareja con la que conviva será de seis meses a un año de prisión, mientras que si la víctima es el hombre y la ofensora la mujer, la pena será de tres meses a un año. La diferencia está, pues, en esos tres meses del límite mínimo de la prisión. La duda de adecuación a la Constitución de esta norma (art. 153.1 Código Penal) se centraba en si ese diferente trato penal lesionaba o no el principio de igualdad constitucional entre mujeres y hombres. ¿Cómo ha argumentado el TC?: (1º) Ha constatado que, en general, el legislador penal tiene una amplia libertad para determinar delitos y penas y que el Tribunal Constitucional debe contenerse a la hora de valorar la política criminal establecida por las Cortes, ciñéndose sólo a los notorios excesos del marco constitucional. (2º Ha sostenido que la diferencia de trato establecida por la norma penal es razonable, por tres motivos: (a) Persigue una finalidad legítima, prevenir las agresiones que en el ámbito de las relaciones de pareja se producen como manifestación del dominio del hombre sobre la mujer. Se trata de luchar contra la violencia de género: "no hay forma más grave de minusvaloración que la que se manifiesta con el uso de la violencia con la finalidad de coartar al otro su más esencial autonomía en su ámbito más personal y de negar su igual e inalienable dignidad". (b) Es una norma adecuada a esa finalidad legítima, por dos motivos: primero, la frecuencia de los delitos de violencia en que la víctima es la mujer, lo que demuestra la mayor necesidad objetiva de protección de ésta; segundo, 
el mayor desvalor (o gravedad) de este tipo de conductas porque "manifiestan la discriminación y la relación de poder de los hombres sobre las mujeres". Hay aquí una violencia peculiar, que merece un mayor reproche, ya que atenta contra la dignidad, seguridad y libertad de las víctimas de un modo más intenso. (c) Es una norma proporcionada o medida, porque la diferencia de trato es escasa (sólo esos tres meses del límite mínimo de la prisión a imponer).

A la sentencia le acompañan cuatro votos discrepantes. Casi todos coinciden en dos ideas de cierta enjundia: ( $1^{a}$ ) La norma penal examinada se funda en la idea (que no comparten) del mayor desvalor de las agresiones de los hombres sobre las mujeres que las de las mujeres sobre los hombres. Esta idea revela una añeja y superada concepción de la mujer como sexo débil. (2a) La sentencia es "interpretativa", es decir, acepta la constitucionalidad de la ley, pero sólo si se entiende que en las agresiones se produce una situación de discriminación o de relación de poder del hombre sobre la mujer, lo cual, sin embargo, ni se hace constar expresamente en el fallo, ni siempre se producirá en la práctica, lo cual provoca inseguridad jurídica en la aplicación por los jueces de la norma (esto es especialmente peligroso en relación con las normas penales).

La doctrina de esta sentencia ha sido reiterada en muchas otras posteriores (76/2008, 80/2008, 81/2008, 82/2008, 83/2008, 95/2008, 96/2008, 97/2008, 98/2008, 99/2008, 100/2008, 45/2009, 107/2009, 127/2009, 151/2009, $152 / 2009,153 / 2009,154 / 2009,164 / 2009,165 / 2009,180 / 2009,201 / 2009$, 202/2009, 213/2009), resolviendo más de cien cuestiones de inconstitucionalidad. Se ha producido aquí, además de un despilfarro (imputable al legislador) de tiempo y recursos públicos, un auténtico referéndum judicial oficioso sobre la deficitaria calidad de la ley en este punto. La profusión de las dudas judiciales es un hecho, además de novedoso y espectacular, sumamente elocuente, sobre todo, si tenemos en cuenta que los órganos judiciales españoles no suelen presentar cuestiones de inconstitucionalidad con facilidad ni frivolidad - entre otras cosas- por la tardanza del TC en resolver. Esto revela que la ley ha sido en este punto una mala ley y que no fue elaborada con la suficiente seriedad ni rigor.

La clave de la lectura que hace el Tribunal Constitucional de las relaciones entre la norma penal cuestionada y el art. 14 de la Constitución se halla en el fundamento jurídico séptimo porque es ahí donde, de modo significativo, va a establecer el estándar o método de decisión. Llegando la lectura de la sentencia a ese fundamento séptimo, cualquier lector ya está en condiciones de saber qué va a fallar el Tribunal. Porque, en línea de disolver más que de resolver problemas, el Tribunal Constitucional va a considerar que la norma cuestionada no plantea conflicto alguno en relación con la prohibición constitucional de discriminación 
por razón de sexo: literal -y sorprendentemente- dirá que "no constituye el sexo de los sujetos activo y pasivo un factor exclusivo (me parece cierto: también otras personas vulnerables pueden ser víctimas, aun siendo varones) o determinante (esto es en lo que no puedo coincidir) de los tratamientos diferenciados".

El conflicto, según el Tribunal Constitucional, no está, como digo, en la prohibición constitucional de discriminación sexual (art. 14b CE), sino en el principio general de igualdad (art. 14a CE). Esta elección del campo de decisión (igualdad general y no prohibición de discriminación sexual), como los juristas más atentos saben, tiene unas consecuencias fundamentales porque el juicio general de igualdad es una técnica de control judicial de la ley muy débil, muy deferente hacia el legislador, que tan sólo exige que la diferenciación jurídica de trato sea razonable. Y ese es, en efecto, el estándar mínimo de control que lleva a cabo el Tribunal: el juicio de razonabilidad -más o menos adornado con algunos elementos del juicio de proporcionalidad-, quizás porque el Tribunal, como le ocurrió con la sentencia de la composición equilibrada de las listas electorales, no estaba completamente satisfecho con su propio modo de argumentar. Mientras que, por el contrario, cualquier limitación de la prohibición constitucional de discriminación sexual, al tratarse de un auténtico derecho fundamental, exige no un simple juicio o estándar de razonabilidad de la diferencia de trato, sino un astringente o estricto juicio de proporcionalidad, con sus requisitos de idoneidad, intervención mínima y proporcionalidad en sentido estricto. Por este camino no ha querido pasar el Tribunal, probablemente porque habrá tenido temor a enfrentarse a la valoración de los requisitos de idoneidad y, sobre todo, de indispensabilidad de la medida. ¿Realmente no había, en el repertorio de respuestas penales, otra solución para luchar contra la violencia de género que castigar de forma distinta según el sexo de los sujetos activo y pasivo las formas más leves de maltrato? Obsérvese que en ninguno de los casos de muertes de mujeres a manos de sus parejas es aplicable la ley.

Lo verdaderamente llamativo es, pues, que en un análisis de un tratamiento penal diferenciado por el sexo de los sujetos activo y pasivo de la conducta criminal, en el contexto de una Ley de violencia de género, el Tribunal Constitucional sostenga que el género no constituye un factor determinante. ¿Qué otro factor lo será, entonces? Al obrar así, la coherencia de la argumentación de la sentencia se fractura inevitablemente porque una parte central de la misma se dirige, en dirección contraria, a convencer de la razonabilidad de que el legislador se enfrente a esta forma específica de violencia hacia las mujeres fundada en convicciones machistas y, por tanto, a intentar encontrar cierto espacio al derecho penal de género. La sentencia ofrece una argumentación sin coherencia interna. Y, por otro lado, 
la idea de la mayor vulnerabilidad de las mujeres o de la mayor culpabilidad de los varones refuerza, más que elimina, estereotipos negativos que recaen sobre las mujeres, la idea de la infirmitas sexus, de sexo débil. De nuevo entra en escena la mirada paternalista sobre la mujer víctima de malos tratos. Evidentemente, existe un síndrome de la mujer maltratada, pero la ley equipara todos los casos de violencia, con lo cual priva de los recursos para proteger eficazmente a los supuestos más graves y habituales.

Me parece que la auténtica ratio decidendi del Tribunal Constitucional es, finalmente, que la diferencia de tratamiento es relativamente pequeña (sólo tres meses del límite inferior de la pena a imponer). En mi opinión, sí existe lugar para un derecho penal de género, pero la medida impugnada ante el Tribunal no es un ejemplo afortunado de él. Cabe una perspectiva de género, sí, pero en el contexto de un Derecho penal igualitario.

En cualquier caso, más allá de la calidad argumentativa de la sentencia, ésta plantea el problema de qué tipo de medida es la norma penal en examen (el Tribunal omite este análisis que, ciertamente, requiere un instrumental conceptual bastante completo y preciso). Para algunos autores, se trataría de una auténtica discriminación positiva, esto es, de un trato (en este caso jurídico-penal) diferente en atención al sexo que, al mismo tiempo que intenta remediar una situación de histórica subordinación femenina, provoca un efecto diferente y perjudicial para los miembros del grupo social mayoritario (en este caso, los varones). A mi juicio, estaríamos en presencia de una medida que intenta evitar una discriminación indirecta en la medida en que un régimen jurídico-penal idéntico para varones y mujeres en el escenario de los malos tratos domésticos produce un trato diferente y peor para las mujeres, puesto que son éstas las víctimas principales de tal tipo de violencia tanto en número como en cualidad, ya que la violencia se funda en la mayoría de las ocasiones en una ideología de género que ve a las mujeres como seres inferiores.

\section{IGUALDAD DE OPORTUNIDADES}

La prohibición de discriminaciones directas e indirectas tiende a exigir la identidad de trato entre hombres y mujeres similarmente situados, aunque de ello no cabe inferir que toda diferenciación jurídica de trato deba ser de interpretación estricta o excepcional. En otras palabras, el mandato de acciones positivas, la igualdad de oportunidades, no es una excepción de la igualdad de trato, sino su necesario complemento.

El Tribunal Constitucional español se ha referido al concepto de acción positiva a partir de la sentencia 128/1987, de 16 de julio. Esta sentencia marca un hito. Antes 
de esta sentencia, podemos hablar de una aproximación "indiferente" respecto del sexo (sex-blind) por parte del TC, pues no distinguía entre principio de igualdad y prohibición de discriminación, de modo que su método de análisis consistía, simplemente, en enjuiciar la razonabilidad de la medida diferenciadora de trato entre hombres y mujeres. La STC 81/1982, de 21 de diciembre, declara contraria al art. $14 \mathrm{CE}$ la ordenanza laboral correspondiente que computaba como horas extraordinarias de las enfermeras todas las que realizaran en domingo, mientras que a sus compañeros varones se les computaba como máximo tres horas de las extraordinarias que efectuaran los domingos (y el resto se incluían dentro del cupo máximo de horas extraordinarias semanales). EL TC no encontró razonables los argumentos que para esa diferencia aportó el Insalud y extendió a los enfermeros varones el régimen de sus compañeras (innovando el ordenamiento y excediéndose, probablemente, de sus competencias).

Con los mismos presupuestos, el TC dicta la sentencia 103/1983, de 22 de noviembre, que declara inconstitucional el art. 160.2 de la Ley General de la Seguridad Social. Este precepto condicionaba el derecho a la pensión de viudedad de los varones a un requisito que no exigía a las viudas: encontrarse incapacitados para el trabajo y vivir a cargo de sus esposas fallecidas. El TC examina los endebles argumentos justificadores de la diferencia y declara discriminatorio este requisito. Nuevamente, lo más discutible de esta sentencia es que innova el ordenamiento (lo que debiera corresponder al legislador), arrojando una importante carga económica a las espaldas de la seguridad social. Es reseñable que el Voto particular de Francisco Rubio a esta sentencia prefigura ya, de algún modo, la idea de compensación que es central en la posterior STC 128/1987 (la ventaja de las viudas sobre los viudos pudo tener su sentido compensador en el pasado respecto de la especial "desigualdad real y efectiva" que sufrían las mujeres en aquel tiempo).

A una solución totalmente distinta conduce, por el contrario, la STC 5/1994, de 17 de enero, que resuelve un asunto de seguridad social complementaria de funcionarios. A juicio del TC, pese a que la regulación de la adquisición de la pensión exigía a los viudos unos requisitos adicionales que no reclamaba para las viudas (que, al tiempo de fallecer sus esposas, se encontraran incapacitados para el trabajo de forma permanente y fueran sostenidos económicamente por ellas), esto no constituye discriminación, pues esa pensión es una prestación complementaria regida por condiciones aceptadas libremente por los mutualistas. De modo que, según el TC, en materia de pensiones de viudedad, el sexo puede operar como criterio de diferenciación siempre que se justifique en una fundamentación razonable (lo que aprecia en el caso). Tal criterio es discutible porque no distingue, como criterio de enjuiciamiento, el principio general de igualdad del test que debe ser 
judicialmente más exigente de la prohibición de discriminación y, además, en el supuesto concreto, se produce una (no apreciada por el TC) discriminación directa por razón de sexo (sobre los varones en esta ocasión) si tenemos en cuenta que la jurisprudencia del Tribunal de Justicia de la Unión, desde la sentencia Barber, de 17 de mayo de 1990, viene considerando que las prestaciones de seguridad social complementaria entran dentro del concepto de "retribución" del art. 119 del Tratado de Roma y de la Directiva 75/117 (preceptos que exigen igualdad de retribución para hombres y mujeres por un trabajo de igual valor).

La sentencia 128/1987 merece, como se decía, un análisis detallado. El actor, un varón que no obtendrá éxito finalmente en su pretensión, recurre en amparo ante el TC por entender que era discriminatorio el distinto régimen de prestaciones en concepto de guardería otorgado por su empleador, el INSALUD: mientras que todas las trabajadoras con hijos menores de seis años, e independientemente de su estado civil, tenían derecho a percibir una prestación por guardería, este derecho se atribuía únicamente a los trabajadores con hijos menores de seis años que fueran viudos. El TC realiza la siguiente interpretación: (10) La lista de posibles motivos de discriminación del art. $14 \mathrm{CE}$, en la que se encuentra el sexo, aunque no es cerrada, sí representa "una explícita interdicción del mantenimiento de determinadas diferenciaciones históricas muy arraigadas y que han situado, tanto por la acción de los poderes públicos como por la práctica social, a sectores de la población en posiciones no sólo desventajosas, sino abiertamente contrarias a la dignidad humana (art. 10.1 CE)". En este sentido, "no debe olvidarse que la expresa exclusión de la discriminación por razón de sexo halla su razón concreta, como resulta de los antecedentes parlamentarios del art. $14 \mathrm{CE}$ y es unánimemente admitido por la doctrina, en la voluntad de terminar con la histórica situación de inferioridad que, en la vida social y jurídica, se había colocado a la población femenina: situación que, en el aspecto que aquí interesa, se traduce en dificultades específicas de la mujer para el acceso al trabajo y su promoción dentro del mismo". Y en este punto de su argumentación, recuerda la sentencia diversos datos estadísticos corroboradores de su afirmación. (2º Esta situación de discriminación se ha intentado paliar en el orden laboral con numerosas medidas de finalidad protectora. Pero hay que distinguir dichas medidas según sean (a) falsamente protectoras o (b) verdaderamente remediadoras o compensadoras. (a) Por una parte, existe un conjunto de medidas que se han adoptado desde una perspectiva que reflejaba los mismos valores sociales que habían mantenido a la mujer en una posición de relegación en el mundo laboral: "partiendo de presupuestos de inferioridad física o de una mayor vocación (u obligación) hacia las tareas familiares, diversas disposiciones han venido a establecer diferencias de trato entre hombres y mujeres en el ámbito 
laboral, que aunque de apariencia protectora, perpetúan y reproducen en la práctica la posición de inferioridad social de la población femenina". (b) Otra cosa son las medidas de acción positiva en favor de la igualdad de las mujeres, que sí son legítimas en el Estado social y democrático de derecho para lograr la efectividad de valores constituciones como la justicia y la igualdad: "La actuación de los poderes públicos para remediar la situación de determinados grupos sociales definidos, entre otras características, por el sexo (y cabe afirmar ahora, en la inmensa mayoría de las veces, por la condición femenina) y colocados en posiciones de innegable desventaja en el ámbito laboral, por razones que resultan de tradiciones y hábitos profundamente arraigados en la sociedad y difícilmente eliminables, no puede considerarse vulneradora del principio de igualdad, aun cuando establezca para ellas un trato más favorable, pues se trata de dar tratamiento distinto a situaciones efectivamente distintas".

La STC 128/1987 imprime, pues, un giro copernicano a la jurisprudencia compensadora: la ilegitimidad constitucional que antes de ella se conectaba a todo tratamiento jurídico (dentro de una concepción sex-blind) que se adoptara tomando como criterio de diferenciación al sexo (otorgando una ventaja o beneficio a un colectivo femenino determinado), se reduce ahora a las medidas paternalistas o falsamente protectoras, que es preciso distinguir cuidadosamente de aquellas otras remediadoras o compensadoras, que sí son válidas. Aunque la presencia del sexo como elemento diferenciador "debe llevar a un más cuidadoso análisis de las causas subyacentes de la diferenciación por ser una causa típica de discriminación del art. $14 \mathrm{CE}$ ", las medidas protectoras de las categorías de trabajadoras que están sometidas a condiciones especialmente desventajosas para su acceso al trabajo o permanencia en él (en comparación con las correspondientes categorías de trabajadores masculinos o con la población trabajadora en general), no podrían considerarse opuestas al citado principio de igualdad, sino al contrario, dirigidas a eliminar la situación de discriminación existente. Es claro que tal diferencia de trato sólo vendrá justificada si efectivamente se dan las circunstancias discriminatorias y sólo en cuanto se den, lo que supone una necesidad de revisión periódica al respecto. Pero si el supuesto de hecho, esto es, la práctica social discriminatoria, es patente, la consecuencia correctora, la diferencia favorable de trato, vendría constitucionalmente justificada. El TC acuña, pues, en la STC 128/1987 el concepto (a la vez que asegura su legitimidad constitucional) de la acción positiva para la igualdad de oportunidades de las mujeres.

El test de la medida paternalista/compensadora, que es el aplicado, con uno u otro nombre, en los países de nuestro entorno, plantea la grave dificultad de su aplicación en la práctica. Un buen ejemplo es la propia STC 128/1987, en 
la que el TC, después de haber establecido, con carácter general, este modelo de análisis, lo vierte al caso en examen concluyendo (de un modo que entendemos muy opinable) que la medida impugnada (el plus de guardería concedido casi en exclusiva a las trabajadoras) no es una medida paternalista (y, por tanto, discriminatoria), sino compensadora, destinada a paliar la discriminación sufrida por las mujeres trabajadoras con hijos pequeños a su cargo ("Este Tribunal no puede ignorar que, pese a las afirmaciones constitucionales, existe una realidad social, resultado de una larga tradición cultural, caracterizada por la atribución en la práctica a la mujer del cuidado de la familia y, particularmente, el cuidado de los hijos. Ello supone un obstáculo muchas veces insalvable para el acceso al trabajo... que se manifiesta en el dato... de la extremadamente baja participación de la mujer casada en la actividad laboral, en comparación con otras categorías sociales"). Pero, ¿hasta qué punto esta medida que reacciona contra la desigualdad de hecho, no la está consolidando, lanzando el mensaje de que los niños corresponden sobre todo a sus madres?

A partir de esta sentencia, el TC empleará, por tanto, el test de las medidas paternalistas/compensadoras.

\section{III.1. Medidas que el TC declara paternalistas o falsamente protectoras de la mujer}

(a) Antes de la STC 128/1987, el Tribunal había sostenido, en la STC $38 / 1986$, de 21 de marzo, que una regulación del descanso nocturno de las trabajadoras (art. 2 del decreto ley de 15 de agosto de 1927) que establecía en su favor un descanso nocturno mínimo y continuo de doce horas (con la sola excepción de clínicas o sanatorios) era contraria al art. $14 \mathrm{CE}$, pues se basaba "en una valoración proteccionista del trabajo de la mujer que no tiene vigencia en la sociedad actual y que no está demostrado que tenga como consecuencia su promoción real y efectiva".

(b) La STC 207/1987, de 22 de diciembre, declara inconstitucional por discriminatoria la norma de un convenio colectivo que otorgaba a las auxiliares de vuelo mayores de treinta y cinco años y menores de cuarenta (pero no a sus compañeros varones) el derecho de retiro anticipado. El TC no niega que, con carácter general, puedan existir actividades laborales en las que la presencia física tenga una importancia decisiva para justificar una diferencia de trato por motivo de sexo, pero no lo aprecia en el caso, ya que la presencia física atractiva que normalmente demanda el personal receptor del servicio de vuelo (argumento que aducía el empleador) no es aplicable en relación con las auxiliares de vuelo.

(c) La STC 142/1990, de 20 de septiembre, cuya doctrina se reitera en las SSTC 158/1990 y 58/1991, invalida el art. 3.1 del decreto ley de 2 de septiem- 
bre de 1955, en cuanto que excluía a los varones de la pensión de viudedad del seguro obligatorio de vejez e invalidez (SOVI). Esta sentencia reproduce, casi en sus propios términos, la argumentación y conclusiones de la STC 103/1983, ya citada.

(d) La STC 28/1992, de 9 de marzo, presenta una estructura semejante a la STC 207/1987: un trabajador varón que recurre una norma de convenio que establecía una ventaja en beneficio exclusivo de las trabajadoras, ventaja que el TC considera discriminatoria, pero si en la STC 207/1987 se otorgaba el amparo, aquí se desestima. El asunto que resuelve la STC 28/1982 es el siguiente: el convenio colectivo de Telefónica concedía un plus de transporte nocturno sólo a sus trabajadoras (hasta 1985, en que se extiende a todos los empleados). El TC considera que dicho plus es una medida paternalista porque no favorece la promoción del trabajo de la mujer, sino que parte de una noción diferenciadora de la mujer, que la supone sujeta a unos riesgos que nunca amenazan al varón, incompatible con el mandato de parificación del art. $14 \mathrm{CE}$. A pesar de considerar a la norma diferenciadora ilegítima, el TC desestima el amparo, precisamente porque al ser ilegítima no puede extenderse a los varones y porque si, pese a todo, se optara por tal extensión, el TC estaría creando una norma nueva, lo que a todas luces excede de su competencia. Recordemos que en las sentencias relativas a pensiones de viudedad el TC ha optado por tal extensión a los varones. La STC 28/1992 acierta, en nuestra opinión, en la fijación de los márgenes de decisión lícitos del propio Tribunal, que son traspasados cuando se amplía a los varones un beneficio (legítimo o no) concedido inicialmente en exclusiva a las mujeres. En estos casos, el Tribunal crea una norma (y casi siempre, además, con un importante impacto económico sobre las arcas públicas). Pero la sentencia 28/1992 deja irresuelto el trato discriminatorio hacia los trabajadores varones, porque reconoce la existencia de una norma colectiva discriminatoria, pero no la invalida. Es decir, la sentencia tolera la existencia en el ordenamiento de una norma que ella misma ha considerado contraria al art. $14 \mathrm{CE}$. Una solución más equilibrada podría haber sido, quizás, declarar nula, por discriminatoria, la norma convencional (y, por tanto, dictar un fallo estimatorio), pero detener ahí el pronunciamiento, no ir más allá ampliando la ventaja al actor y a los demás trabajadores varones de la empresa. Y ello, porque las medidas falsamente protectoras de las mujeres no sólo las discriminan a ellas, al considerarlas seres de inferior valor, por eso mismo necesitados de mayor protección, sino también a ellos, a sus compañeros varones. No procede, a nuestro juicio, igualar por arriba, extendiendo esta ventaja (inicialmente sólo para mujeres) a los varones, ni dejar subsistente la discriminación, incluso advertida (como hace la STC 28/1982), sino igualar por abajo: anular el acto o 
norma discriminatoria para todos, mujeres y hombres, pues a todos perjudica en realidad. La STC 28/1992 ofrece también otro ejemplo del carácter en gran medida tautológico del test de la medida paternalista/compensadora. En efecto, no exterioriza un examen complejo o detenido de por qué un plus de transporte nocturno otorgado sólo a las trabajadoras es una medida paternalista. Varias páginas del Código Penal demuestran una mayor inseguridad de las mujeres ante la posibilidad de ataques físicos e incluso el Tribunal Constitucional federal alemán, en su sentencia de 28 de enero de 1992 (que declaró contraria a la Ley Fundamental la prohibición del trabajo nocturno de las mujeres), al valorar el argumento en favor de dicha prohibición del riesgo especial al que están sujetas las mujeres, reconoció que "acaso podrían evitarse estos riesgos especiales poniendo a su disposición un autobús para los desplazamientos que hayan de realizar por motivo de su trabajo nocturno". La distinción entre medidas paternalistas y compensadoras es siempre difícil y opinable, pero exige de los Tribunales una exposición de argumentos que no sea meramente circular.

(e) La STC 3/1993, de 14 de enero, anula el art. 162.2 de la Ley General de la Seguridad Social, que reconocía sólo a las hijas y hermanas, pero no a hijos y hermanos, el derecho a percibir ciertas prestaciones. El TC vuelve a extender a los varones la ventaja concedida inicialmente sólo a las mujeres. Con el agravante, en este caso, de que, a diferencia de lo que ocurría con la pensión de viudedad, la propia sentencia considera aquella ventaja como ilegítima o discriminatoria: la medida diferenciadora no tiene la función de reincorporar a la mujer al trabajo, ni su emancipación de las tareas domésticas, sino que es una medida compensadora de un estado de necesidad en el que predomina la visión paternalista y la función sustitutiva de la pensión perdida. Por ello, afirma la sentencia, se trata de una prestación que, adoptada por el factor de diferenciación sexual, resulta perturbadora para lograr una igualdad efectiva de la mujer en relación con el varón, en tanto que privilegio instituido en favor de la misma que se revela como una forma encubierta de discriminación que se vuelve contra ella.

(f) La STC 315/1994, de 28 de noviembre, es semejante, en cuanto al supuesto que examina, a la STC 68/1991, de 8 de abril: una pensión de orfandad que concedía un reglamento local navarro a los hijos varones de empleados municipales hasta los veinticinco años y a las hijas hasta que "tomaren estado civil o religioso, sea cualquiera su edad". Ahora bien, la STC 68/1991 estima el recurso de amparo solicitado por una de estas hijas frente a la denegación administrativa de dicha pensión (el Ayuntamiento interpretaba el precepto reglamentario, a la luz del art. $14 \mathrm{CE}$, entendiendo que sólo deberían tener derecho a la pensión las mujeres que, sin empleo, carecieran de suficientes medios de subsistencia; por cierto que esta 
misma interpretación fue defendida tanto por el Tribunal Supremo como por el Voto discrepante que acompaña a la sentencia, de los magistrados Álvaro Rodríguez Bereijo y Eugenio Díaz Eimil). A juicio del TC, es "cuando menos probable" que el precepto reglamentario que introduce la distinción sea discriminatorio, pero de ello "no puede extraerse, sin embargo, otra consecuencia que la de que no puede denegarse, con apoyo en la norma discriminatoria, un derecho que ésta concedería si no lo fuera"; de modo que, mientras exista esa norma (aunque de apariencia discriminatoria), y en tanto el legislador no la modifique, "el encargado de aplicarla no puede privar a nadie del derecho que ésta le otorga, aunque pueda eventualmente reconocerlo también a quienes, según el texto literal de la misma, no lo tendrían, inaplicando las cláusulas que establecen la discriminación”. Esta STC 68/1991 mantiene, en definitiva, la legitimidad de un trato favorable a las hijas de los empleados municipales respecto de los hijos, argumentando no desde la doctrina anterior del TC sobre la discriminación por razón de sexo (test de la medida paternalista/compensadora), sino a partir de la idea de que los aplicadores del Derecho no pueden privar a nadie del derecho otorgado por una norma (aunque pudiera incurrir en discriminación), en tanto no sea modificada o derogada. Estamos en presencia, pues, de otra solución distinta que ofrece el TC al complejo problema de la reparación jurídica de las discriminaciones: se reconoce que la discriminación "probablemente" existe en favor de un grupo de mujeres, pero no se extiende a los varones similarmente situados (línea de la jurisprudencia sobre pensiones), ni se desestima el amparo aunque se reconozca la discriminación (solución de la STC 28/1992, sobre plus de transporte nocturno), sino que se reconoce la discriminación, pero, pese a todo, se otorga el amparo. En nuestra opinión, la norma era claramente discriminatoria por paternalista o falsamente protectora y, en consecuencia, el TC debiera haber declarado nula y derogada la norma reglamentaria preconstitucional, por incompatible con el art. $14 \mathrm{CE}, \mathrm{y}$ haber desestimado el amparo.

Pues bien, en la STC 315/1994 el actor era un varón que solicitaba, con apoyo en la jurisprudencia del TC sobre discriminación por sexo en materia de pensiones, una equiparación "por arriba" con las mujeres similarmente situadas, esto es, que se extendiera también a los hijos varones de los empleados municipales navarros el régimen más favorable para el disfrute de la pensión de orfandad concedido inicialmente a las mujeres. Muy acertadamente, el TC desestimará el amparo porque el principio de igualdad "no siempre es motor de una generalización del régimen más favorable y, muy al contrario, puede exigir la supresión del beneficio si éste fuere injustificado y no razonable, dando origen a una situación privilegiada con base a un criterio diferencial incompatible con el sistema de valores latentes en la 
Constitución"; de modo que el principio de igualdad "no puede ser un medio para adquirir derechos ajenos en virtud del agravio comparativo... no resulta posible una parificación en la discriminación misma”.

(g) La STC 317/1994, de 28 de noviembre, es reseñable no tanto por la solución concreta a la que llega (que sigue el test típico), como por su intento de sistematizar criterios para distinguir las medidas paternalistas o falsamente protectoras de las legítimas medidas de acción positiva para el fomento de la igualdad de las mujeres. La sentencia desestima el amparo, cuyo contenido era la petición de aplicación de una norma pre-constitucional que otorgaba a ciertas trabajadoras el derecho a una indemnización por ruptura del contrato de trabajo a consecuencia de su matrimonio. El TC declara dicha norma falsamente protectora y, por tanto, confirma la corrección de la decisión de los órganos judiciales ordinarios de considerarla derogada por la Constitución. La sentencia aporta dos criterios generales para distinguir una medida paternalista de otra de acción positiva: (10) que la medida no sea contraria al principio de igualdad de trato, es decir, "que no tenga por efecto anular o alterar la igualdad de oportunidades o de trato en el empleo"; y que $\left(2^{\circ}\right)$ no haya perdido su razón de ser, esto es, "que no tienda a perpetuar estereotipos o patrones culturales ya superados". Aplicados estos criterios al caso, la Sala concluyó que la norma en examen era discriminatoria, porque provocaba la pérdida de igualdad de oportunidades en el empleo (al incentivar la interrupción de la carrera profesional de la mujer) y porque habría perdido su razón de ser en una sociedad como la actual.

\section{III.2. Medidas que el TC ha considerado acciones positivas legitimas}

Estas decisiones (cuyo paradigma, por lo menos hasta las importantes sentencias de 2008 a las que más tarde me referiré, es la tanta veces citada STC 128/1987), son particularmente interesantes, porque constituyen el auténtico banco de pruebas del reconocimiento de la licitud constitucional de las acciones positivas.

(a) En el asunto que da origen a la STC 19/1989, el actor (varón) alegaba que las normas de los estatutos de la mutualidad laboral sobre pensión de jubilación en el sector textil aplicables a su caso (que habían sido derogados ya hacía mucho tiempo antes, pero que perduraron en el tiempo a través de normas transitorias) eran discriminatorias porque establecían una sensible diferencia entre hombres y mujeres cuando la jubilación se producía entre los sesenta y los sesenta y cuatro años (la de la mujer podía llegar a ser un $80 \%$ del salario regulador y la del varón podía alcanzar como máximo el 70\%). El TC declara que esta diferencia no es discriminatoria, pues se aplicaba en un sector de actividad en el que, por aquellas fechas, la mujer trabajadora estaba sujeta a inferiores condiciones de trabajo y 
salario, y adscrita a categorías profesionales de menor calificación. El TC recuerda que la norma enjuiciada se inscribía en un contexto normativo que se decía comprometido en "liberar" a la mujer casada "del taller y de la fábrica" (Declaración II del Fuero del Trabajo) y que, en su conjunto, bien mediante cláusulas de excedencia forzosa de la mujer por razón de su matrimonio, bien mediante reglas de fomento del empleo de "padres" o "cabezas" de familia (condición que se predicaba, ante todo, del varón), había colocado a las mujeres en una clara situación de inferioridad en el mercado de trabajo. El TC sostiene que la diferencia impugnada no tenía por objeto colocar al trabajador varón en peores condiciones en el momento de su jubilación, sino compensar de algún modo la situación de inferioridad que, laboral y socialmente, venía padeciendo el personal femenino. No obstante, hay que tener en cuenta que el TC para justificar esta diferencia de trato valora muy significativamente el carácter limitado, excepcional o "histórico" de la medida. Posiblemente, si hubiera estado vigente en el tiempo en el que se dicta la sentencia, el TC habría razonado de otro modo.

(b) La STC 109/1993, de 25 de marzo, cuya doctrina se reitera en la STC 187/1993, de 14 de junio, resuelve una cuestión de inconstitucionalidad planteada respecto del art. 37.4 del Estatuto de los Trabajadores: "Las trabajadoras, por lactancia de un hijo menor de nueve meses, tendrán derecho a una hora de ausencia del trabajo que podrá dividir en dos fracciones. La mujer, por su voluntad, podrá sustituir este derecho por una reducción de la jornada normal en media hora con la misma finalidad". Hay que tener en cuenta que después del planteamiento de la duda de constitucionalidad ante el TC, se amplió el precepto: "Este permiso podrá ser disfrutado indistintamente por el padre o por la madre en el caso de que ambos trabajen". Por ello, la relevancia práctica de la sentencia, cuando se dicta en 1993, es ya muy reducida. En el proceso a quo, un trabajador varón que atendía ordinariamente la lactancia de su hijo (su mujer no podía hacerlo al tener que desplazarse diariamente para trabajar lejos del domicilio familiar) había reclamado contra su empresa porque ésta le autorizó la ausencia para alimentar al hijo, pero no se la retribuía. La STC 109/1993 sostiene la constitucionalidad de la norma impugnada, considerando que su objetivo es hacer compatible para la mujer su trabajo y el cuidado de sus hijos recién nacidos. La medida no implica una visión de la mujer como ser inferior en el trabajo, sino "una ventaja de apoyo a la mujer como grupo desfavorecido", de una compensación, derivada del art. 9.2 CE. "No puede afirmarse genéricamente -indica el TC- que cualquier ventaja legal otorgada a la mujer sea siempre discriminatoria para el varón por el mero hecho de no hacerle partícipe de la misma (como podría al contrario serlo para la mujer la que le impusiera una privación solamente por su sexo)". Antes bien, "la justificación 
de tal diferencia podría hallarse en una situación de desventaja de la mujer que se trata de compensar; en este caso, porque ello tiene lugar frente a la relación de trabajo; y sin perjuicio de que el legislador pueda extender el beneficio al varón o incluso suprimirlo sin que ello se oponga tampoco a los preceptos constitucionales invocados". La sentencia basa su conclusión de que la conservación del permiso de lactancia en exclusiva para las trabajadoras es una medida compensadora de una situación de específica desventaja de la mujer trabajadora, en que la lactancia natural (como el embarazo y el parto) es una realidad biológica diferencial. $Y$ aunque admite que en el caso de la lactancia artificial también el varón puede prestar ese cuidado al hijo y que acaso la medida en examen lleva consigo el riesgo de consolidar una división sexista de papeles en las responsabilidades familiares, sostiene su constitucionalidad en la medida en que, siendo una norma laboral (que no se refiere, pues, al reparto de responsabilidades entre padre y madre), su objetivo es hacer compatible para la mujer su trabajo y el cuidado del hijo recién nacido.

Esta argumentación dividió al TC; al Voto particular de Vicente Gimeno se adhirieron otros tres magistrados: Fernando García-Mon, Carlos de la Vega y Eugenio Díaz Eimil. Para ellos, el precepto cuestionado discriminaba claramente por razón de sexo a los trabajadores varones (que pueden alimentar artificialmente a sus hijos) y también a las mismas trabajadoras, pues si bien la finalidad tuitiva de la norma pudo encontrarse en su origen remoto (una ley de 1944), desde el momento en que se instaura dicho derecho y se otorga exclusivamente a la mujer trabajadora, "aquella finalidad se vuelve contra ella misma, ya que a nadie se le oculta que para un empresario poco escrupuloso con el principio de igualdad, siempre le será 'más rentable' contratar a hombres que a mujeres trabajadoras dado el incremento de los costes laborales que por esta causa y por otras biológicas (vg. las bajas por maternidad) las mujeres siempre ocasionan".

Lo afirmado en el Voto discrepante parece más acorde con la realidad sociolaboral actual; la concesión en exclusiva a la trabajadora del permiso de lactancia es hoy, probablemente y si tenemos en cuenta los dos criterios que más tarde aportará la STC 317/1994 (que la diferencia no anule o altere la igualdad de oportunidades o de trato en el empleo de las mujeres y que no tienda a perpetuar estereotipos ya superados - del tipo: el cuidado de los hijos corresponde sólo o preponderantemente a las madres-), más una medida falsamente protectora que una auténtica medida de acción positiva. Pero en todo caso, y más allá de la duda (casi metafísica) de si se trata de una medida paternalista o, por el contrario, compensadora, lo cierto es que en la STC 109/1993 no podemos encontrar un asidero seguro del reconocimiento por parte del TC de las acciones positivas. La 
ventaja cuestionada dudosamente podría considerarse una ventaja; y ni siquiera estaba en vigor al tiempo de ser dictada la sentencia. Dado que, como hemos visto, la STC 19/1989 tampoco es un ejemplo válido del reconocimiento de las acciones positivas, podemos concluir que, hasta la fecha, la única sentencia que ha mantenido una regulación favorable en exclusiva a las mujeres también para el futuro (y no sólo para situaciones pasadas) ha sido la STC 128/1987. En otras palabras, esta última sentencia, que es mecánicamente citada por el TC en muchos de los casos de discriminación por razón de sexo, incluso en la jurisprudencia de igualdad de trato o de equiparación (lo cual no tiene mucho sentido: una mujer puede trabajar en el interior de una mina no porque se la compense de nada, ni se la fomente positivamente una igualdad de oportunidades, sino porque no existe ninguna razón válida para que no lo haga en condiciones de igualdad con los varones), ha originado una línea jurisprudencial ¡que, en realidad, sólo ha sido seguido por ella! Y no deja de ser curioso que las dos principales medidas que el TC ha considerado compensatorias hayan sido, precisamente, un plus de guardería y el permiso de lactancia, dos "ventajas" más orientadas a que la mujer compatibilice su actividad laboral con las actividades domésticas y familiares, que a promocionarla efectivamente en el trabajo extradoméstico (que es donde, en realidad, reside el problema social de la desigualdad).

En una sentencia reciente, la 12/2008, de 29 de enero, sobre composición equilibrada de mujeres y hombres en listas electorales (cuya doctrina se reitera en la sentencia 13/2009, de 19 de enero), el Tribunal se enfrenta a un caso claro de igualdad de oportunidades (aunque formalmente, como veremos, la medida controvertida era exquisitamente neutral en cuanto al sexo), pero ya no se apoyará en la doctrina compensatoria de la sentencia 128/1987 (que parece estar en desuso), sino directamente en el art. 9.2 de la Constitución (que ordena a los poderes públicos promover la igualdad real y efectiva).

La sentencia resuelve la impugnación (por una cuestión de inconstitucionalidad planteada por el Juzgado de lo Contencioso-Administrativo número 1 de Sta. Cruz de Tenerife y un recurso presentado por más de 50 diputados del Grupo parlamentario popular) de la disposición adicional segunda de la Ley Orgánica 3/2007, de 22 de marzo, para la igualdad efectiva de mujeres y hombres, que introdujo un nuevo artículo en la LOREG, el art. 44 bis, según el cual las candidaturas de las elecciones al Congreso, las Asambleas territoriales, el Parlamento europeo y los entes locales deberán tener una "composición equilibrada" de mujeres y hombres, de forma que en el conjunto de la lista los candidatos de cada uno de los sexos supongan como mínimo el 40\%. Esta proporción (que podrá ser mayor en las listas autonómicas) deberá mantenerse en cada tramo de 5 puestos y en las listas 
de suplentes. La regla no será exigible en los municipios con 3.000 habitantes o menos (art. 187.2 LOREG).

El Tribunal examina en primer lugar los argumentos de derecho comparado, observando que la igualdad formal y material entre mujeres y hombres es "una piedra angular del derecho internacional de los derechos humanos" (Convención sobre eliminación de todas las formas de discriminación contra la mujer de 18/12/79; Convenio de Roma), así como del Derecho comunitario (Tratado de Lisboa, aún no en vigor: art. 1 bis, la igualdad entre mujeres y hombres se añade como valor fundamental de la Unión). Pero estos textos no se pronuncian, en principio, sobre los instrumentos utilizables por los Estados para darles cumplimiento. Frente al argumento de que en Francia e Italia tuvieron que reformar sus Constituciones para acoger una medida similar, la sentencia considera que nuestro ordenamiento se diferencia del francés y del italiano por la amplitud del art. 9.2 CE, que se proyecta expresamente a la participación política y que a la idea de "remover" añade las de "promover" y "facilitar". Esta idea es discutible ( ¿ "remover" no permite también "promover"?), pero lo curioso es que (hasta donde sé, sin precedentes) se utilice derecho extranjero directamente como parámetro de interpretación de nuestras normas constitucionales.

El Tribunal sostiene que la medida impugnada no establece una medida de discriminación inversa o compensatoria (favoreciendo a un sexo sobre otro), sino una fórmula de equilibrio entre sexos, que tampoco es estrictamente paritaria, en cuanto no impone una total igualdad entre hombres y mujeres, sino una proporción máxima de 60 a 40\%. Su efecto es, pues, bidireccional en cuanto que esa proporción se asegura igualmente a uno y otro sexo. Por otro lado, el nuevo requisito tiene como destinatarios directos a los partidos, coaliciones y agrupaciones de electores (se plantea, sobre todo, en el ámbito del art. $6 \mathrm{CE}$ y $9.2 \mathrm{CE}$ ) y no a los ciudadanos: no es una condición de elegibilidad, por lo que no afecta al derecho de sufragio pasivo individual (no afecta directamente al art. $23 \mathrm{CE}$ ). Evidentemente, aquí está el punto clave de la sentencia, ya que se muestra el campo interpretativo en el que va a operar (no en el de los derechos fundamentales, sino en el campo de los principios de organización electoral). El Tribunal considera que la medida es adecuada al mandato de igualdad real y efectiva del art. 9.2 CE, "toda vez que los partidos políticos, como asociaciones cualificadas por sus funciones constitucionales (sujetos que concurren a la manifestación y formación de la voluntad popular) son cauce válido para el logro de la sustantivación de la igualdad propugnada por el art. 9.2 CE”.

La medida, a juicio del Tribunal, no supone un tratamiento peyorativo de ninguno de los sexos, ni siquiera plasma un tratamiento diferenciado en razón 
del sexo. Aunque esto es formalmente así, me parece que se trata de una medida que es una acción positiva materialmente, esto es, por su contenido, su finalidad y ubicación en una Ley de igualdad de trato y de oportunidades entre mujeres y hombres. De hecho, el propio Tribunal, tras afirmar que la cuota electoral no "plasma un tratamiento diferenciado en razón del sexo", sostiene más adelante que "el 44 bis LOREG persigue la efectividad del art. $14 \mathrm{CE}$ en el ámbito de la representación política, donde si bien hombres y mujeres son formalmente iguales, es evidente que las segundas han estado siempre materialmente preteridas".

Declarada la conformidad de la norma impugnada con el derecho de igualdad, el Tribunal pasa a examinar otros aspectos problemáticos, empezando por la libertad de presentación de candidaturas por los partidos. La sentencia observa que no es, ni puede ser, absoluta. Ya el legislador, en atención a otros valores y bienes constitucionales, ha limitado esta libertad imponiendo a los partidos determinadas condiciones para la confección de las candidaturas: elegibilidad de los candidatos, residencia, listas cerradas y bloqueadas. Esta nueva limitación por razón del sexo no es la única ni carece, por lo que acaba de verse, de fundamento constitucional. Esta constricción es perfectamente constitucional porque $\left(1^{\circ}\right) \mathrm{Ni}$ siquiera esa libertad es un derecho fundamental, sino una atribución, implícita en la Constitución (art. $6 \mathrm{CE}$ ). (2) Es legítima (por el fin de conseguir la igualdad efectiva en el terreno de la participación política: arts. 9.2, 14 y $23 \mathrm{CE}$ ). (3a) Es razonable el régimen instrumentado por el legislador que se limita a exigir una composición equilibrada con un mínimo del 40\%, con excepciones para poblaciones de menos de 3.000 habitantes y de 5.000 para las elecciones municipales anteriores a 2011 (4\%) Es inocua para los derechos fundamentales de quienes siendo sus destinatarios, los partidos políticos, no son, por definición, titulares de los derechos fundamentales de sufragio activo y pasivo.

Resta por examinar la objeción de mayor calado, la compatibilidad de esta medida con el derecho fundamental de asociación. Según el Tribunal, la normativa cuestionada no atañe a la vertiente individual del derecho fundamental, por lo que se debe descartar que produzca intromisión en la libertad positiva (libertad de creación de asociaciones o de adscripción a una ya creada) o en la negativa (libertad de no asociarse y de dejar de pertenecer a alguna), o en la dimensión "inter privatos" (garantía de un haz de facultades a los asociados frente a las asociaciones a las que pertenezcan o pretendan incorporarse). Tampoco afecta a la libertad relativa a la organización y funcionamiento internos, dado que "no versa sobre ninguna faceta de la vida interna ordinaria de los partidos políticos". De modo que, a juicio del TC, ninguna de las 4 dimensiones de la libertad de asociación se ve afectada. En mi opinión, sin embargo, decidir los candidatos forma parte de la libertad de organización de los partidos. 
La sentencia completa su razonamiento sosteniendo que tampoco se ve afectada la libertad ideológica y de expresión de los partidos (arts. 16.1 y 20.1 a), porque no lesiona la ideología feminista, que puede seguir existiendo, sólo que no podrá hacer "testimonio feminista" con la presentación de listas integradas sólo por mujeres. En el nuevo contexto normativo, afirma el Tribunal, es ya innecesario compensar la mayor presencia masculina con candidaturas exclusivamente femeninas por la sencilla razón de que aquel desequilibrio histórico deviene un imposible. La norma no impide la existencia de partidos con una ideología contraria (machista o feminista) a la igualdad efectiva entre los ciudadanos. De ser así la medida sería inconstitucional, ya que en nuestro sistema no tiene cabida un modelo de "democracia militante" que imponga la adhesión positiva al ordenamiento y, en primer lugar, a la Constitución. La medida no implica la exigencia de que los partidos participen de los valores sobre los que se sustenta la llamada democracia paritaria. Además, los partidos que no compartan esta medida, podrán modificarla en el futuro.

Por último, considera el Tribunal que tampoco se fragmenta el cuerpo electoral, ni se quiebra la unidad de la categoría de ciudadano ni se disuelve el interés general en un conjunto de intereses parciales o por categorías. El principio de composición equilibrada se asienta sobre un criterio natural y universal, como es el sexo. Esto no supone la creación de vínculos especiales entre electores y elegibles, ni la compartimentación del cuerpo electoral en función del sexo. No cabe atender el argumento de los recurrentes de que el requisito de la paridad perjudica a la unidad del pueblo soberano: el cuerpo electoral no se confunde con el titular de la soberanía (el pueblo español), aunque su voluntad se exprese a través de él.

El voto discrepante de J. Rodríguez-Zapata se opone a las tesis de la sentencia. En su opinión, es válido que los partidos acojan en sus estatutos cláusulas que aseguren la participación de la mujer en las listas electorales, pero la imposición por ley de la paridad o de cuotas electorales vulnera el principio de la representación política y la libertad ideológica y de autoorganización de los partidos, resultando lesionado el derecho de sufragio pasivo de los candidatos propuestos que queden excluidos de participar en el proceso electoral como consecuencia de la aplicación de la norma cuestionada.

El nuevo modelo de representación política, según el voto discrepante, interpone la condición sexual entre la soberanía y la condición de ciudadano. ¿Es concebible dividir a los representantes en categorías con el fin de facilitar o asegurar un mínimo de elegidos de cada una sin que resulte gravemente afectado el principio de la unidad y homogeneidad del cuerpo de ciudadanos? Si se admite que sí, el legislador podrá en un futuro imponer al cuerpo electoral que en las 
candidaturas figuren otras minorías (raza, lengua, orientación sexual, religión, minusvalías, juventud, tercera edad, etc.). En otros países, con normas sustancialmente idénticas, han tenido que reformar previamente sus Constituciones (los elementos estructurales de la democracia han de ser fruto del consenso).

No me resulta convincente la tesis metodológica central de la sentencia, según la cual la medida controvertida no afecta derechos fundamentales. Al Tribunal le resulta útil esta afirmación, porque a partir de ella no necesita argumentar desde el astringente juicio de proporcionalidad, bastándole el de mera razonabilidad. Ciertamente, el formato de la medida es sensato y equilibrado (marcando un porcentaje indistinto por sexo de 60\%/40\%) y esto también viene en su ayuda. Pero la elección de candidatos en las listas es una decisión que forma parte del derecho de asociación de los partidos y de su libertad ideológica y, por consiguiente, afecta a derechos fundamentales. El Tribunal podría haber alcanzado la misma conclusión y fallo (la compatibilidad de la medida con la Constitución), quizá argumentando desde la exigencia constitucional (art. $6 \mathrm{CE}$ ) de que la organización y el funcionamiento de los partidos sean democráticos, pero el razonamiento que emplea en la sentencia no me acaba de seducir.

La doctrina de la sentencia 12/2008 se viene a reproducir más tarde en la sentencia 13/2009, de 19 de enero, aunque en este último caso hay interesantes matices diferenciales. El primero es que no sólo se refiere al sistema electoral, sino también a la función pública y el segundo es que, en materia electoral, la disposición impugnada fijaba una representación mínima en las listas de candidatos electorales de mujeres del 50\% y de hombres del 40\%. Veamos ambos aspectos. En cuanto al primero, el Tribunal examina tres asuntos. La ley vasca impugnada ordenaba, en primer lugar, a la Administración seguir la valoración del cumplimiento del mandato de una representación equilibrada (entendiendo por tal un porcentaje por género indistinto del 60/40\%) en la composición de todos los órganos de la Administración (el Tribunal no lo considera inconstitucional porque se trata tan sólo de un mandato, no de una regla); en segundo lugar, establecía que los miembros de los órganos encargados de los procesos de acceso, provisión y promoción en el empleo público de la Comunidad Autónoma vasca también respetaran esa composición equilibrada (la sentencia tampoco lo considera inconstitucional, porque los miembros de tales órganos deben reunir los requisitos de mérito y capacidad y porque esta regla se puede excepcionar si se justifica debidamente su no pertinencia); y, por último, se estipulaba que los jurados de premios y de adquisición de fondos culturales y/o artísticos también fueran equilibrados (lo cual, como es obvio, tampoco ha sido estimado inconstitucional). 
En relación con el sistema electoral del Parlamento vasco y de las instituciones forales, la ley impugnada establecía que las listas de candidatos estuvieran integradas por, al menos, un 50\% de mujeres (en el conjunto de cada lista y en cada tramo de seis nombres). El Tribunal considera, en primer término, que esta disposición no vulnera lo dispuesto en la normativa básica estatal, que exige la presencia de un $40 \%$ de mujeres o de hombres, pero que permite "incrementos autonómicos”. Es más, la disposición vasca es razonable porque, leída conjuntamente con la estatal, se garantiza que como mínimo el $40 \%$ de los candidatos sean varones. Ciertamente, la disposición impugnada determina que la presencia mínima de hombres en las listas electorales sea del $40 \%$ y la de las mujeres del $50 \%$, pero el Tribunal encuentra esta diferencia plenamente justificada por dos razones: $\left(1^{a}\right)$ con ella se pretende corregir una situación histórica de discriminación de las mujeres en la vida pública; y (2a) la medida es adecuada porque no comporta un sacrificio innecesario de derechos fundamentales: ni la diferencia de porcentaje es excesiva, ni está en cuestión alguna un derecho de los hombres o de los partidos políticos. Como cabe suponer, a esta sentencia le acompaña un voto discrepante semejante al de la sentencia 12/2008; Rodríguez-Zapata reitera su crítica al impacto negativo de la democracia de género sobre el principio de representación política.

\section{A MODO DE CONCLUSIÓN}

Así pues, en general, la jurisprudencia del Tribunal Constitucional español en materia de prohibición de discriminación por razón de sexo (a diferencia de otros rasgos "sospechosos", como la raza/etnia) es abundante y garantista (en algunos aspectos como, por ejemplo, la tutela de las trabajadoras embarazadas, más que en otros). De modo que puede valorarse positivamente en líneas generales. Sin embargo, no puede decirse que responda a modelos conceptuales excesivamente depurados. La jurisprudencia ha ido creciendo por aluvión, adaptándose a la solución de los casos concretos, casi siempre correcta, pero sin caracterizarse especialmente por un manejo preciso de las categorías del Derecho Antidiscriminatorio. 
